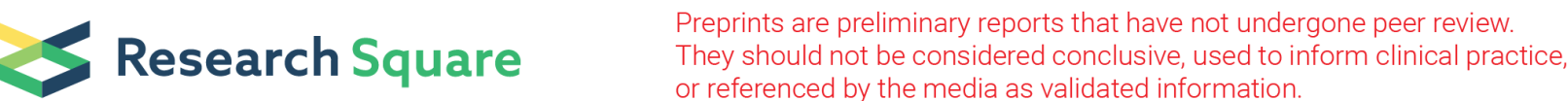

\section{Efficacy and Safety of Antithrombotic Therapy With Non-Vitamin K Antagonist Oral Anticoagulants After Transcatheter Aortic Valve Replacement: A Systematic Review and Meta-Analysis}

Qing An

Southern Medical University https://orcid.org/0000-0001-8959-2652

Shuwen Su

Southern Medical University

Yan Tu

Southern Medical University

Lingfeng Gao

Southern Medical University

Gaopeng Xian

Southern Medical University

Yujia Bai

Southern Medical University

Qiong Zhan

Southern Medical University

Xingbo Xu

University Medical Center of Göttingen, Georg-August-University

Dingli $X u$

Southern Medical University

Qingchun Zeng ( $\nabla$ qingchunzeng@smu.edu.cn )

Southern Medical University

\section{Research Article}

Keywords: TAVR, NOACs, APT, VKAs

Posted Date: May 6th, 2021

DOl: https://doi.org/10.21203/rs.3.rs-404977/v1

License: (9) This work is licensed under a Creative Commons Attribution 4.0 International License.

Read Full License 
Version of Record: A version of this preprint was published at Therapeutic Advances in Chronic Disease on January 1st, 2021. See the published version at https://doi.org/10.1177/20406223211056730. 


\section{Abstract}

Purpose: We performed a meta-analysis to compare the efficacy and safety of antithrombotic therapy with non-vitamin K antagonist oral anticoagulants (NOACs) versus standard care in patients after successful transcatheter aortic valve replacement (TAVR).

Methods: A systematic search of PubMed, Cochrane Central Register of Controlled Trials, EMBASE databases and ClinicalTrials.gov Website (through Oct 21, 2020) was performed. Risk ratio (RR) with 95\% confidence intervals $(\mathrm{Cl})$ for all outcomes were calculated using random-effects models.

Results: Twelve studies comprising 6,943 patients were included (5,299 had indications for OAC while 1,644 didn't). No significant differences were found between NOACs and the standard care in all stroke, a composite endpoint and major/life-threatening bleeding. NOACs were associated lower all-cause mortality than VKAs for post-TAVR patients with indications for OAC after more than 1-year follow-up (RR $=0.64,95 \% \mathrm{Cl}:[0.42,0.96], p=0.03)$ while NOACs were poorer than APT for patients without indications for OAC (RR $=1.66,95 \% \mathrm{Cl}:[1.12,2.45], p=0.01)$. As for the impact to prevent valve thrombosis, NOACs and VKAs were not significantly different for patients with indications for OAC (RR $=0.66,95 \% \mathrm{Cl}$ : [0.24, 1.84], $p=0.43)$ while NOACs were better than APT for patients without indications for OAC $(R R=0.19$, $95 \% \mathrm{Cl}:[0.04,0.83], \mathrm{p}=0.03)$.

Conclusions: For patients with indications for OAC, post-TAVR antithrombotic therapy with NOACs were more favorable due to its lower all-cause mortality after more than 1-year follow-up. For those without indications for OAC, NOACs were poorer due to its higher all-cause mortality.

\section{Introduction}

For patients with severe symptomatic aortic stenosis (AS), transcatheter aortic valve replacement (TAVR) is considered to be the standard care for those who are at moderate to high surgical risk [1] and the U.S. Food and Drug Administration (FDA) approved expanding the indication for TAVR to low-risk patients on August 16, 2019 [2].

Thromboembolic complications, such as stroke, systemic embolism, valve thrombosis, and venous thromboembolism, have been reported after TAVR [3], and subclinical leaflet thrombosis may be associate with an increased incidence of cerebrovascular disease [4]. Therefore, the optimal antithrombotic regimen after TAVR is urgently needed, but the recent antithrombotic regimen remains controversial and empirically based. According to current American guidelines, aspirin 75 to $100 \mathrm{mg}$ daily is reasonable (class of recommendation lla, level of evidence B-R) while treatment with low-dose rivaroxaban (10 mg daily) plus aspirin (75-100 mg) is contraindicated (III, B-R) based on the GALILEO trial for TAVR patients without indications for oral anticoagulation (OAC). For patients with atrial fibrillation (AF) and other indications for OAC, currently, vitamin K antagonists (VKAs) therapy with a continuation of aspirin has been considered as standard care and should be administered on the basis of the patient's $\mathrm{CHA}_{2} \mathrm{DS}_{2}$-VASc score (Supplementary Table 1). Patients at low bleeding risk may be 
administered 3- to 6-month dual antiplatelet therapy (DAPT) with aspirin 75 to $100 \mathrm{mg}$ and clopidogrel 75 $\mathrm{mg}$ (Ilb, B-NR) or anticoagulation with a VKAs to achieve an INR of 2.5 for at least 3 months after TAVR (IIb, B-NR). European guidelines are slightly different, endorsing DAPT for 3-6 months after TAVR (Ila, C), or single antiplatelet therapy in high bleeding risk patients (IIb, C) [1,5-7].

Non-vitamin K antagonist oral anticoagulants (NOACs) have been demonstrated to reduce the incidence of thromboembolism in different clinical settings [8]. However, the need for routine use of NOACs to prevent thromboembolic events in post-TAVR patients without indications for OAC was not welldocumented. Moreover, for those with indications for OAC, whether using NOACs or VKAs as anticoagulants in antithrombotic therapy, remains unclear and is actively debated, despite the more favorable efficacy profile of NOACs than VKAs in patients with non-valvular atrial fibrillation [9]. This study was performed to compare the efficacy and safety of antithrombotic therapy with NOACs versus standard care after TAVR and search for the optimal antithrombotic therapy.

\section{Methods}

This systematic review and meta-analysis were carried out under the pre-specified protocol (PROSPERO: CRD42020215578) and standards in preferred reporting items for systematic reviews and meta-analyses (PRISMA) statement [10].

\section{Search strategy}

We searched the PubMed, Cochrane Central Register of Controlled Trials (CENTRAL), EMBASE databases and ClinicalTrials.gov Website systematically for relevant studies from the very beginning to October 21 , 2020. Reference list of the whole included studies were independently screened to search for extra studies omitted in the primary search. Full details of the search strategy were presented in Supplementary Table 2.

\section{Study selection}

Two investigators (QA and SS) selected the studies manually and independently by EndNote X9.3.3 software. All the included studies must be up to the PICOS criteria (participants/disease, intervention/exposure, comparison/control, outcomes/endpoints, and study design): (1) participants/disease: post-TAVR patients both with and without indication for long-term OAC. (2) intervention/exposure: NOACs were utilized as antithrombotic therapy. (3) comparison/control: VKAs or APT without NOACs were used as antithrombotic therapy. (4) outcomes/endpoints: the primary outcome is all-cause mortality. The secondary outcomes were composed of two parts. One was the efficacy outcomes which was composed of all stroke, valve thrombosis (reduced leaflet motion ( $\geq 50 \%$ reduction) or the presence of hypoattenuated leaflet thickening (HALT)), and a composite endpoint that was defined as the composite of death, stroke or thromboembolic events. The other was the safety outcome including major/life-threatening bleeding. All the recorded outcomes were defined according to the Valve Academic Research Consortium-2 (VARC-2) criteria [11]. (5) study design: randomized controlled trials (RCTs), 
controlled (non-randomized) clinical trials (CCTs) and cohort studies. Studies that were not completed or presented only with abstract were excluded.

\section{Data extraction and quality assessment}

Two investigators (QA and SS) independently extracted data from the eligible studies with the use of the pre-designed data extraction tables in Microsoft Excel, which consisted of study characteristics (first author, publication year and study design), whether anticoagulant indications exist or not, baseline clinical characteristics (patient demographics, $\mathrm{CHA}_{2} \mathrm{DS}_{2}$-VASc score and HAS-BLED score (Supplementary Table 3)), and data on outcomes of interests ( total number, occurrence number and mean/ median follow-up time).

The methodological quality of the included studies was assessed independently by two investigators (QA and SS). Qualities of RCTs, CCTs and cohort studies were assessed according to the Cochrane Collaboration Risk of Bias Tool (ROB), Methodological index for non-randomized studies (MINORS) and Newcastle-Ottawa Scale (NOS) respectively [12-14]. Any disagreement in all processes mentioned above was resolved by the additional researcher (QZ).

\section{Data analysis}

The measure of effect for the all outcomes was risk ratio (RR) with $95 \%$ confidence intervals (Cls). Data was pooled by using Mantel-Haenszel random-effects model and $p<0.05$ was regarded as statistically significant difference. We conducted the analysis in patients with and without an indication for long-term OAC respectively because these two cohorts are very different in risk profiles and need for antithrombotic drugs. The heterogeneity between studies was evaluated with Cochran's $Q$ test and $I^{2}$ index $\left(I^{2} \geq 50 \%\right.$ indicates heterogeneity, and $p \leq 0.1$ shows significant difference). Subgroup analysis according to follow-up time (more than one year) were applicated in the pooled outcomes with existing heterogeneity. Only if no less than ten studies were included could we employ meta-regression and contour enhanced funnel plot to inspect the source of heterogeneity and possible publication bias. Significant publication bias would be further explored by Egger's test. Sensitivity analysis was utilized to judge the stability of ultimate results. When there was significant high heterogeneity $\left(I^{2} \geq 50 \%\right)$, cumulative analyses with O'Brien-Fleming sequential monitoring boundaries were supplemented and the Baujat plot was used to explore the source of heterogeneity. RevMan 5.4.1 was utilized to pool the data, perform subgroup analysis and assess the quality of the included RCTs. STATA 16.0 was utilized to perform metaregression, do sensitivity analysis and assess the publication bias. Trial Sequential Analysis (TSA).jar and R x64 3.6.3 were used to do cumulative analyses and the Baujat plot.

\section{Results}

1. Selection of studies and evaluation of quality 
The primary search identified 2,171 records after excluding duplicates. Subsequently, 45 records were left after excluding 2,126 records by reviewing titles and abstracts carefully according to the principle of PICOS. After reading full-text, 33 records were excluded for specific reasons listed in Fig. 1 Finally, 12 studies with 6,943 patients in total met the inclusion criteria, which included 2 RCTs [3, 15], 1 nonrandomized clinical trial [16] and 9 cohort studies [17-25].

Both of the two RCTs were evaluated as high quality (Supplementary Fig. 1), the CCT had global ideal score being 19(>16) (Supplementary Table 4), and the whole cohort studies were considered of high quality because of the scores ranging from 6 to 9 , with an average of 7.30 (Supplementary Table 5).

2. Studies characteristics and baseline characteristics of patients

Patients' characteristics were displayed in Supplementary Table 6. The common demographic and baseline characteristics, such as mean age (with average of 82 years old), body mass index (BMI) and the percentages of female, diabetes mellitus, hypertension were similar between NOACs group and VKAs/APT group. The coronary artery disease (CAD), previous hemorrhagic or ischemic stroke, previous venous or arterial thromboembolism, permanent pacemaker and chronic obstructive pulmonary disease (COPD), which may have important impact on the procedure and prognosis of TAVR; the $\mathrm{CHA}_{2} \mathrm{DS}_{2}-\mathrm{VASc}$ score and HAS-BLED score that can affect the selection of antithrombotic therapy and the outcomes of studies; the glomerular filtration rate (GFR) and the percentage of chronic renal failure, which reflected kidney function and related to the choice of NOACs dose[9], were similar between the above two groups. A total of 6,943 post-TAVR patients (5,299 in 10 studies had indications for OAC; 1,644 in 2 studies didn't have indications for OAC) were covered in this study. Indeed, GALILEO-4D was a substudy of GALILEO trial. After reading protocols and supplementary appendixes of two RCTs, we divided the patients included in the GALILEO into two parts: those who participated in the GALILEO-4D and those who did not. Then data extraction was performed in two parts respectively. The detailed data of outcomes in studies were shown in Supplementary Table 7.

3. NOACs therapy versus standard care (VKAs/APT for patients with/without indications for OAC).

\subsection{The primary outcome (all-cause mortality)}

Mantel-Haenszel random-effects model was utilized to pool the data of 4006 patients with indications for OAC (1459 received NOACs versus 2547 received VKAs) and 1644 patients without indications for OAC (826 received NOACs versus 818 received APT) from ten eligible studies. As shown in Fig. 2, no significant differences existed between NOACs and VKAs (RR $=0.85,95 \% \mathrm{Cl}:[0.61,1.18], p=0.32)$, but NOACs were associated with higher risk of all-cause mortality than APT ( $R R=1.66,95 \%$ Cl: $[1.12,2.45], p$ $=0.01$. .

$\mathrm{Cl}$ (confidence intervals), NOACs (non-vitamin K antagonist oral anticoagulants), OAC (oral anticoagulation) 
Subgroup analysis was performed because of significant high heterogeneity $(12=68 \%, p=0.002)$ in studies with indications for OAC, and we demonstrated that NOACs were connected with the lower risk of all-cause of mortality than VKAs after more than 1-year follow-up $(\mathrm{RR}=0.64,95 \% \mathrm{Cl}:[0.42,0.96], p=0.03$, Fig. 3)

$\mathrm{Cl}$ (confidence intervals), NOACs (non-vitamin $\mathrm{K}$ antagonist oral anticoagulants), OAC (oral anticoagulation)

Cumulative analyses were supplemented with O'Brien-Fleming sequential monitoring boundaries because of significant high heterogeneity in the subgroup with follow-up time no more than $12 \mathrm{~m}\left(\mathrm{I}^{2}=58 \%, \mathrm{P}=\right.$ 0.05). As shown in Fig. 4, Z-curve and O'Brien-Fleming futility boundaries intersect at the last point, which indicated that NOACs and VKAs were associated with similar all-cause mortality if follow-up time was no more than one year and this conclusion was stably. In the future, more clinical trials should be followed up for more than one year.

TSA (Trial Sequential Analysis)

Contour enhanced funnel plot was completed to inspect possible publication bias, and significant publication bias was further explored by Egger's test. As a result, there were no significant publication bias ( $p=0.2949$, Fig. 5$)$.

RR (risk ratio)

\subsection{The secondary outcomes}

\section{The efficacy outcomes}

For the efficacy outcomes including all stroke, valve thrombosis and a composite endpoint, MantelHaenszel random-effects model was utilized to pool the data from nine, four and seven studies. As shown in Fig. 6, no significant differences existed in all the efficacy outcomes between NOACs and VKAs for patients with indications for OAC. For patients without indications for OAC, no significant differences existed in all stroke and a composite endpoint between NOACs and APT, but NOACs were better than APT to prevent valve thrombosis $(\mathrm{RR}=0.19,95 \% \mathrm{Cl}$ : $[0.04,0.83], \mathrm{p}=0.03)$.

Cumulative analyses were supplemented with O'Brien-Fleming sequential monitoring boundaries because of significant high heterogeneity in a composite endpoint (with indications for OAC) $\left(I^{2}=66 \%, P=0.02\right)$. As shown in Fig. 7, the results may be false negative and more clinical trials were needed.

$\mathrm{Cl}$ (confidence intervals), NOACs (non-vitamin $\mathrm{K}$ antagonist oral anticoagulants), OAC (oral anticoagulation)

TSA (Trial Sequential Analysis)

2. The safety outcome (major/life-threatening bleeding) 
We utilized Mantel-Haenszel random-effects model to analyze the data of 4,005 patients with indications for OAC (1459 received NOACs versus 2546 received VKAs) and 1,644 patients without indications for OAC (826 received NOACs versus 818 received APT) from ten eligible studies. No significant differences were discovered between NOACs therapy and standard care (Fig. 8).

$\mathrm{Cl}$ (confidence intervals), NOACs (non-vitamin $\mathrm{K}$ antagonist oral anticoagulants), OAC (oral anticoagulation)

\section{Discussion}

This study indicated that all-cause mortality after the use of NOACs was lower than VKAs in post-TAVR patients with indications for OAC and more than 1-year follow-up, while it was higher than APT in those without indications for OAC. No significant differences were discovered between NOACs and standard care in all stroke, a composite endpoint and major/life-threatening bleeding. As for valve thrombosis, the equal effect was shown between NOACs and VKAs while NOACs possessed a better protective effect than APT.

Patients being considered for TAVR are adults with Calcific aortic valve stenosis (CAVS) rather than those with congenital AS, rheumatic valve disease or isolated aortic regurgitation [1]. CAVS is becoming a growing economic and health burden due to its bleak prognosis in symptomatic patients [26, 27]. No pharmacotherapy has a remarkable effect on holding or delaying the disease, and the precise and specific molecular mechanism of the pathophysiological underlying CAVS remains insufficient, although growing pharmacological treatment targets were uncovered, such as the vitamin K-dependent matrix Glaprotein (MGP), which is an effective inhibitor of vascular calcification [28], and the presence of macrophages [29]. Therefore, aortic valve replacement seems to be the only available treatment option and the TAVR was used widely. Firstly, stroke is the most dreadful ischemic/embolic cerebrovascular complication after TAVR, which occupies up to $7 \%$ of patients within the first year [30]. The need for antithrombotic therapy has been emphasized due to the stable stroke rate within the past decade [31]. A high thromboembolic burden, such as pre-existing/new-onset atrial fibrillation and mechanical movement of debris falling during the TAVR, raises the incidence of stroke during or after the procedure [32, 33]. Secondly, several observational studies suggested that valve thrombosis may be related to increased risk of cerebrovascular events and reduced the long-term durability of transcatheter heart valves [15, 34-36]. Thirdly, the risk of major/life-threatening bleeding, obviously connecting to a poor prognosis [37]. Consistent with the baseline patients' characteristics of this studies, it is well known that CAVS has been thought to be a degenerative disease and the vast majority of post-TAVR patients are the old [38]. The balance between thrombogenesis and bleeding is more complex since a variety of underlying diseases and medication restrictions in the old. All of these demonstrated a remarkable essentiality of optimal antithrombotic therapy for post-TAVR patients, especially for those who have indications for OAC.

It's worth noting that, although, VKAs is used widely to prevent the thrombo-embolic events within postTAVR patients with indications for OAC, calcification cannot be ignored as a side effect [27]. Vitamin $\mathrm{K}$ is 
one of the most essential elements of our body. It is not only involved in blood coagulation but also associated with various vitamin $\mathrm{K}$-dependent proteins relating to the anticancer effect, inflammation, bone metabolism, vascular calcification and so on. For instance, in blood vessels, the formation of hydroxyapatite, the apoptosis of vascular smooth muscle cells (VSMCs) and the transdifferentiation of VSMCs to osteoblasts can be reduced by vitamin K2 [39-42]. The adverse reaction of VKAs that the use of VKAs demonstrated more vascular/valvular calcification was confirmed in animal models and humans [43-46]. Many practical inconveniences, such as multiple interactions between food and drug, narrow therapeutic window and the need of regular monitor, hinder the use of VKAs, especially for those multimorbid and old [21]. All of the above may be one reason for the lower all-cause mortality of NOACs compared with warfarin after long-term follow-up time. On the other hand, the control of bleeding, which used to be insufficient in NOACs, has made great progress in recent years. Methods were comprised of dose adjustment of the agents in renal dysfunction, avoiding the concomitant use of other antithrombotic agents if feasible, nonspecific hemostatic agents and the specific reversing agents were significant steps to minimize bleeding risks with NOACs $[9,47,48]$. What's more, based on the noninferiority of NOACs, the latest guideline clearly stated that NOACs is an effective alternative to VKA [5]. This study showed that NOACs were more favorable than VKAs for patients with indications for OAC when there were no contraindications.

Consistent with current American guidelines, this study suggested that NOACs were contraindicated for those without indications for OAC despite the advantage of preventing valve thrombosis. However, NOACs or VKAs may be used to resolve reduced leaflet motion ( $\geq 50 \%$ reduction)[34].

There was no significant high heterogeneity in this study except for all-cause mortality (with indications for OAC and no more than $12 \mathrm{~m}$ follow-up) and a composite endpoint (with indications for OAC). We conducted a subgroup analysis of the latter (Supplementary Fig. 2), but significant heterogeneity still existed. The Baujat plot was used to explore the source of heterogeneity (Supplementary Fig. 3), and we found the study of Butt et al. and Jochheim et al. provided the highest contribution to overall heterogeneity of the former and the latter respectively. Therefore, data was pooled again after excluding the study of Butt et al. and Jochheim et al. respectively, as shown in Supplementary Fig. 4, the results were steady and the heterogeneity were not high.

Given the extremely short follow-up time (3d), data was pooled again after excluding the study of Yanagisawa et al. and the results were steady (Supplementary Fig. 5).

We performed sensitivity analysis and cumulative analyses of all-cause mortality (with indications for OAC and more than 12m follow-up, Supplementary Fig. 6 and Supplementary Fig. 7), and the results indicated that recent studies tended to report a lower all-cause mortality of NOACs than VKAs after more than 1-year follow-up. However, this may be false positive. The use of NOACs becomes more and more standardized and reasonable with the updating of researches and guidelines, especially the dose adjustments of NOACs in patients with chronic kidney disease [9]. The latest study of Kawashima et al. excluded patients with estimated glomerular filtration rates $<30 \mathrm{ml} / \mathrm{min} / 1.73 \mathrm{~m}^{2}$ who were not eligible 
for DOACs and reduced the doses of rivaroxaban according to creatinine clearance, while the study of Kalogeras et al. and Kosmidou et al. didn't specialize the renal function of the included patients. All of above may be the source of no-significant heterogeneity and the reason why recent studies tend to report a lower all-cause mortality of NOACs. The upcoming ATLANTIS trial and the other clinical trials may show more information.

\section{Limitations}

We searched the database comprehensively and simultaneously to evaluate the efficacy and safety of antithrombotic therapy with NOACs for post-TAVR patients with or without indications for OAC. However, there were still some limitations. Firstly, there were only two studies included in the subgroup without indications for OAC. However, there were some clinical trials on the way to completing, such as REDOX TAVI (NCT04171726) and ADAPT-TAVR (NCT03284827), which would enrich the further study. Secondly, all of the studies included in subgroup with indications for OAC were not RCTs. Therefore, two ongoing RCTs, ENVISAGE-TAVI AF (NCT02943785) and AVATAR (NCT02735902), were expected to be published for updating the present study. Thirdly, there were inconsistencies in doses and duration of NOACs since some of studies were anticoagulation therapy alone while the others were anticoagulation plus double/single antiplatelet drug therapy. All of this may be confounding factors and therefore influence the outcomes. Fourthly, all of the included studies with indications for OAC focused on AF, therefore, more RCTs and the studies focused on the other indications for OAC rather than AF are expected to clarify the optimal antithrombotic regimen after TAVR for patients in different conditions. Lastly, most of the included studies focused on the use of rivaroxaban, so further studies were needed to explore the details of different NOACs.

\section{Conclusions}

Based on the currently available studies, we concluded that NOACs of antithrombotic therapy might be a better choice for patients with indications for OAC due to its superiority in reducing all-cause mortality (more than 1-year follow-up), noninferiority in the other aspects and the limitations of VKAs, and standard care with APT is a better antithrombotic therapy for patients lack of indications for OAC. In the future, RCTs are expected to verify the conclusion and determine the optimal antithrombotic therapy

\section{Declarations}

1.Funding: This project was partly supported by the Science and Technology Program of Guangzhou (201804010086, 201707020012) (QZ \& DX), the National Natural Science Foundation of China (82070403, 81770386) (QZ), the Frontier Research Program of Guangzhou Regenerative Medicine and Health Guangdong Laboratory (2018GZR110105001) (QZ) and the Youth Science and Technology Innovation Talent of Guangdong TeZhi Plan (grant number 2019TQ05Y136) (QZ). 
2.Conflicts of interest/Competing interests: All authors certify that they have no affiliations with or involvement in any organization or entity with any financial interest or non-financial interest in the subject matter or materials discussed in this manuscript.

3.Availability of data and material: The data that support the findings of this study are available from the corresponding author upon reasonable request.

4.Code availability: We used the meta-analysis sections of RevMan 5.4.1, STATA 16.0, TSA.jar and R x64 3.6.3.

5.Authors' contributions: Conceptualization: [All authors]; Data curation: [Qing An], [Shuwen Su] and [Qingchun Zeng]; Formal Analysis: [Qing An], [Yan Tu], [Lingfeng Gao] and [Gaopeng Xian]; Funding acquisition: [Qingchun Zeng]; Investigation: [All authors]; Methodology: [Qing An], [Lingfeng Gao] and [Xingbo Xu]; Project administration: [Qing An], [Shuwen Su] and [Qingchun Zeng]; Resources: [Qingchun Zeng] and [Dingli Xu]; Software: [Qing An], [Gaopeng Xian], [Yujia Bai] and [Qiong Zhan]; Supervision: [Xingbo Xu], [Dingli Xu] and [Qingchun Zeng]; Validation: [All authors]; Visualization: [Qing An], [Shuwen Su], [Yan Tu] and [Gaopeng Xian]; Writing - original draft: [Qing An], [Shuwen Su], [Yan Tu], [Lingfeng Gao] and [Gaopeng Xian]; Writing - review \& editing: [Yujia Bai], [Qiong Zhan], [Xingbo Xu], [Dingli Xu] and [Qingchun Zeng]. All authors read and approved the final manuscript to be published. All authors agreed to be accountable for all aspects of the work in ensuring that questions related to the accuracy or integrity of any part of the work are appropriately investigated and resolved.

6.Ethical approval: Not applicable. The ethical approval is N/A because this meta-analysis is not associated with ethic.

7.Consent to participate: Not applicable.

8.Consent for publication: Not applicable.

\section{References}

1. Otto CM, Kumbhani DJ, Alexander KP, et al. 2017 ACC Expert Consensus Decision Pathway for Transcatheter Aortic Valve Replacement in the Management of Adults With Aortic Stenosis: A Report of the American College of Cardiology Task Force on Clinical Expert Consensus Documents. J Am Coll Cardiol. 2017. https://doi.org/10.1016/j.jacc.2016.12.006.

2. Kaul S. Raising the Evidentiary Bar for Guideline Recommendations for TAVR: JACC Review Topic of the Week. J Am Coll Cardiol. 2020. https://doi.org/10.1016/j.jacc.2020.05.085.

3. Dangas GD, Tijssen JGP, Wöhrle J, et al. A Controlled Trial of Rivaroxaban after Transcatheter AorticValve Replacement. N Engl J Med. 2020. https://doi.org/10.1056/NEJMoa1911425.

4. Kahlert P, Knipp SC, Schlamann M, et al. Silent and apparent cerebral ischemia after percutaneous transfemoral aortic valve implantation: a diffusion-weighted magnetic resonance imaging study. Circulation. 2010. https://doi.org/10.1161/circulationaha.109.855866. 
5. Otto CM, Nishimura RA, Bonow RO, et al. 2020 ACC/AHA Guideline for the Management of Patients With Valvular Heart Disease: A Report of the American College of Cardiology/American Heart Association Joint Committee on Clinical Practice Guidelines. J Am Coll Cardiol. 2020. https://doi.org/10.1016/j.jacc.2020.11.018.

6. January CT, Wann LS, Calkins H, et al. 2019 AHA/ACC/HRS Focused Update of the 2014 AHA/ACC/HRS Guideline for the Management of Patients With Atrial Fibrillation: A Report of the American College of Cardiology/American Heart Association Task Force on Clinical Practice Guidelines and the Heart Rhythm Society in Collaboration With the Society of Thoracic Surgeons. Circulation. 2019. https://doi.org/10.1161/cir.0000000000000665.

7. Baumgartner $\mathrm{H}$, Falk V, Bax JJ, et al. 2017 ESC/EACTS Guidelines for the management of valvular heart disease. Eur Heart J. 2017. https://doi.org/10.1093/eurheartj/ehx391.

8. Kearon C, Akl EA, Ornelas J, et al. Antithrombotic Therapy for VTE Disease: CHEST Guideline and Expert Panel Report. Chest. 2016. https://doi.org/10.1016/j.chest.2015.11.026.

9. Hindricks G, Potpara T, Dagres N, et al. 2020 ESC Guidelines for the diagnosis and management of atrial fibrillation developed in collaboration with the European Association of Cardio-Thoracic Surgery (EACTS). Eur Heart J. 2020. https://doi.org/10.1093/eurheartj/ehaa612.

10. Liberati A, Altman DG, Tetzlaff J, et al. The PRISMA statement for reporting systematic reviews and meta-analyses of studies that evaluate healthcare interventions: explanation and elaboration. Bmj. 2009. https://doi.org/10.1136/bmj.b2700.

11. Kappetein AP, Head SJ, Généreux P, et al. Updated standardized endpoint definitions for transcatheter aortic valve implantation: the Valve Academic Research Consortium-2 consensus document. J Am Coll Cardiol. 2012. https://doi.org/10.1016/j.jacc.2012.09.001.

12. Higgins JP, Altman DG, Gøtzsche PC, et al. The Cochrane Collaboration's tool for assessing risk of bias in randomised trials. Bmj. 2011. https://doi.org/10.1136/bmj.d5928.

13. Slim K, Nini E, Forestier D, Kwiatkowski F, Panis Y, Chipponi J. Methodological index for nonrandomized studies (minors): development and validation of a new instrument. ANZ J Surg. 2003. https://doi.org/10.1046/j.1445-2197.2003.02748.x.

14. Weis S, Kesselmeier M, Davis JS, et al. Cefazolin versus anti-staphylococcal penicillins for the treatment of patients with Staphylococcus aureus bacteraemia. Clin Microbiol Infect. 2019. https://doi.org/10.1016/j.cmi.2019.03.010.

15. De Backer O, Dangas GD, Jilaihawi H, et al. Reduced Leaflet Motion after Transcatheter Aortic-Valve Replacement. N Engl J Med. 2020. https://doi.org/10.1056/NEJMoa1911426.

16. Seeger J, Gonska B, Rodewald C, Rottbauer W, Wöhrle J. Apixaban in patients with atrial fibrillation after transfemoral aortic valve implantation compared with vitamin $\mathrm{K}$ antagonist [Conference Abstract]. J Am Coll Cardiol. 2016, https://www.embase.com/search/results? subaction=viewrecord\&id=L614161358\&from=export.

17. Butt JH, Backer O, Olesen JB, et al. Vitamin K Antagonists versus Direct Oral Anticoagulants After Transcatheter Aortic Valve Implantation in Atrial Fibrillation [Article in Press]. Eur Heart $\mathrm{J}$ Cardiovasc 
Pharmacother. 2019. https://doi.org/10.1093/ehjcvp/pvz064.

18. Geis NA, Kiriakou C, Chorianopoulos E, Uhlmann L, Katus HA, Bekeredjian R. NOAC monotherapy in patients with concomitant indications for oral anticoagulation undergoing transcatheter aortic valve implantation. Clin Res Cardiol. 2018. https://doi.org/10.1007/s00392-018-1247-x.

19. Jochheim D, Barbanti M, Capretti G, et al. Oral Anticoagulant Type and Outcomes After Transcatheter Aortic Valve Replacement. JACC Cardiovasc Interv. 2019. https://doi.org/10.1016/j.jcin.2019.03.003.

20. Kalogeras K, Jabbour RJ, Ruparelia N, et al. Comparison of warfarin versus DOACs in patients with concomitant indication for oral anticoagulation undergoing TAVl; results from the ATLAS registry [Article]. J Thromb Thrombolysis. 2020. https://doi.org/10.1007/s11239-019-01968-w.

21. Kawashima $\mathrm{H}$, Watanabe $\mathrm{Y}$, Hioki $\mathrm{H}$, et al. Direct Oral Anticoagulants Versus Vitamin $\mathrm{K}$ Antagonists in Patients With Atrial Fibrillation After TAVR. JACC Cardiovasc Interv. 2020; https://doi.org/10.1016/j.jcin.2020.09.013.

22. Kosmidou I, Liu Y, Alu MC, et al. Antithrombotic Therapy and Cardiovascular Outcomes After Transcatheter Aortic Valve Replacement in Patients With Atrial Fibrillation. JACC Cardiovasc Interv. 2019. https://doi.org/10.1016/j.jcin.2019.06.001.

23. Mangner N, Crusius L, Haussig S, et al. Continued Versus Interrupted Oral Anticoagulation During Transfemoral Transcatheter Aortic Valve Implantation and Impact of Postoperative Anticoagulant Management on Outcome in Patients With Atrial Fibrillation [Article]. American journal of cardiology. 2019. https://doi.org/10.1016/j.amjcard.2018.12.042.

24. Tang L, Lesser JR, Schneider LM, et al. Prospective Evaluation for Hypoattenuated Leaflet Thickening Following Transcatheter Aortic Valve Implantation [Article]. American journal of cardiology. 2019. https://doi.org/10.1016/j.amjcard.2018.11.012.

25. Yanagisawa R, Tanaka M, Yashima F, et al. Early and late leaflet thrombosis after transcatheter aortic valve replacement: A multicenter initiative from the OCEAN-TAVI registry [Article]. Circulation: Cardiovascular Interventions. 2019. https://doi.org/10.1161/CIRCINTERVENTIONS.118.007349.

26. Lindman BR, Clavel MA, Mathieu P, et al. Calcific aortic stenosis. Nat Rev Dis Primers. 2016. https://doi.org/10.1038/nrdp.2016.6.

27. Peeters F, Meex SJR, Dweck MR, et al. Calcific aortic valve stenosis: hard disease in the heart: A biomolecular approach towards diagnosis and treatment. Eur Heart J. 2018. https://doi.org/10.1093/eurheartj/ehx653.

28. Schurgers LJ, Uitto J, Reutelingsperger CP. Vitamin K-dependent carboxylation of matrix Gla-protein: a crucial switch to control ectopic mineralization. Trends Mol Med. 2013. https://doi.org/10.1016/j.molmed.2012.12.008.

29. Hutcheson JD, Aikawa E, Merryman WD. Potential drug targets for calcific aortic valve disease. Nat Rev Cardiol. 2014. https://doi.org/10.1038/nrcardio.2014.1.

30. Vranckx P, Windecker S, Welsh RC, Valgimigli M, Mehran R, Dangas G. Thrombo-embolic prevention after transcatheter aortic valve implantation. Eur Heart J. 2017. https://doi.org/10.1093/eurheartj/ehx390. 
31. Guedeney P, Mehran R, Collet JP, Claessen BE, Ten Berg J, Dangas GD. Antithrombotic Therapy After Transcatheter Aortic Valve Replacement. Circ Cardiovasc Interv. 2019. https://doi.org/10.1161/circinterventions.118.007411.

32. Van Mieghem NM, Schipper ME, Ladich E, et al. Histopathology of embolic debris captured during transcatheter aortic valve replacement. Circulation. 2013. https://doi.org/10.1161/circulationaha.112.001091.

33. Mangieri A, Montalto C, Poletti E, et al. Thrombotic Versus Bleeding Risk After Transcatheter Aortic Valve Replacement: JACC Review Topic of the Week. J Am Coll Cardiol. 2019. https://doi.org/10.1016/j.jacc.2019.08.1032.

34. Chakravarty T, Søndergaard L, Friedman J, et al. Subclinical leaflet thrombosis in surgical and transcatheter bioprosthetic aortic valves: an observational study. Lancet. 2017. https://doi.org/10.1016/s0140-6736(17)30757-2.

35. Sannino A, Hahn RT, Leipsic J, Mack MJ, Grayburn PA. Meta-analysis of Incidence, Predictors and Consequences of Clinical and Subclinical Bioprosthetic Leaflet Thrombosis After Transcatheter Aortic Valve Implantation. Am J Cardiol. 2020. https://doi.org/10.1016/j.amjcard.2020.07.018.

36. Makkar RR, Fontana G, Jilaihawi $\mathrm{H}$, et al. Possible Subclinical Leaflet Thrombosis in Bioprosthetic Aortic Valves. N Engl J Med. 2015. https://doi.org/10.1056/NEJMoa1509233.

37. Piccolo R, Pilgrim T, Franzone A, et al. Frequency, Timing, and Impact of Access-Site and Non-AccessSite Bleeding on Mortality Among Patients Undergoing Transcatheter Aortic Valve Replacement. JACC Cardiovasc Interv. 2017. https://doi.org/10.1016/j.jcin.2017.04.034.

38. Nkomo VT, Gardin JM, Skelton TN, Gottdiener JS, Scott CG, Enriquez-Sarano M. Burden of valvular heart diseases: a population-based study. Lancet. 2006. https://doi.org/10.1016/s01406736(06)69208-8.

39. Villa JKD, Diaz MAN, Pizziolo VR, Martino HSD. Effect of vitamin K in bone metabolism and vascular calcification: A review of mechanisms of action and evidences. Crit Rev Food Sci Nutr. 2017. https://doi.org/10.1080/10408398.2016.1211616.

40. Stenflo J, Fernlund P, Egan W, Roepstorff P. Vitamin K dependent modifications of glutamic acid residues in prothrombin. Proc Natl Acad Sci U S A. 1974. https://doi.org/10.1073/pnas.71.7.2730.

41. Ivanova D, Zhelev Z, Getsov P, et al Vitamin K. Redox-modulation, prevention of mitochondrial dysfunction and anticancer effect. Redox Biol. 2018. https://doi.org/10.1016/j.redox.2018.03.013.

42. Ferland G. The discovery of vitamin K and its clinical applications. Ann Nutr Metab. 2012. https://doi.org/10.1159/000343108.

43. Weijs $B$, Blaauw $Y$, Rennenberg RJ, et al. Patients using vitamin $K$ antagonists show increased levels of coronary calcification: an observational study in low-risk atrial fibrillation patients. Eur Heart J. 2011. https://doi.org/10.1093/eurheartj/ehr226.

44. Schurgers LJ, Aebert $H$, Vermeer $C$, Bültmann B, Janzen J. Oral anticoagulant treatment: friend or foe in cardiovascular disease? Blood. 2004. https://doi.org/10.1182/blood-2004-04-1277. 
45. Price PA, Faus SA, Williamson MK. Warfarin causes rapid calcification of the elastic lamellae in rat arteries and heart valves. Arterioscler Thromb Vasc Biol. 1998.

https://doi.org/10.1161/01.atv.18.9.1400.

46. Andrews J, Psaltis PJ, Bayturan O, et al. Warfarin Use Is Associated With Progressive Coronary Arterial Calcification: Insights From Serial Intravascular Ultrasound. JACC Cardiovasc Imaging. 2018; https://doi.org/10.1016/j.jcmg.2017.04.010.

47. Ruff CT, Giugliano RP, Antman EM. Management of Bleeding With Non-Vitamin K Antagonist Oral Anticoagulants in the Era of Specific Reversal Agents. Circulation. 2016.

https://doi.org/10.1161/circulationaha.116.021831.

48. Pollack CV Jr, Reilly PA, van Ryn J, et al. Idarucizumab for Dabigatran Reversal - Full Cohort Analysis. N Engl J Med. 2017. https://doi.org/10.1056/NEJMoa1707278.

\section{Figures}




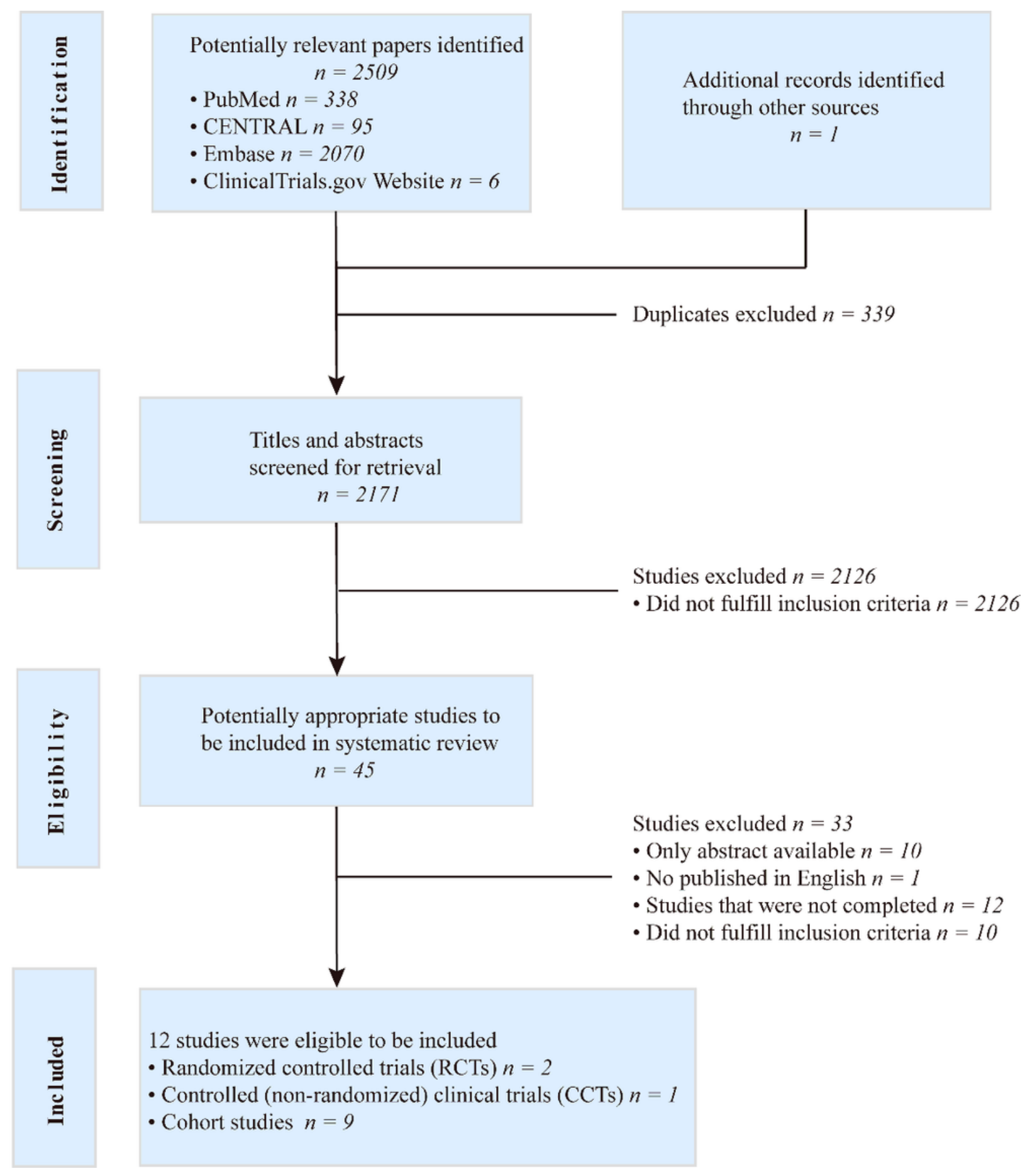

\section{Figure 1}

Flow chart for selection of eligible studies 
NOACs standard care Risk Ratio

Study or Subgroup Events Total Events Total Weight M-H, Random, 95\% Cl with indications for OAC

$\begin{array}{lrrrrrr}\text { Butt,2019 } & 15 & 219 & 54 & 516 & 10.7 \% & 0.65[0.38,1.13] \\ \text { Geis,2018 } & 12 & 154 & 11 & 172 & 8.0 \% & 1.22[0.55,2.68] \\ \text { Jochheim,2019 } & 54 & 326 & 78 & 636 & 13.5 \% & 1.35[0.98,1.86] \\ \text { Kalogeras,2020 } & 13 & 115 & 16 & 102 & 9.1 \% & 0.72[0.36,1.42] \\ \text { Kawashima,2020 } & 23 & 227 & 41 & 176 & 11.6 \% & 0.43[0.27,0.70] \\ \text { Kosmidou,2019 } & 33 & 155 & 207 & 778 & 13.4 \% & 0.80[0.58,1.11] \\ \text { Mangner,2019 } & 16 & 182 & 16 & 117 & 9.4 \% & 0.64[0.33,1.23] \\ \text { Seeger,2017 } & 19 & 81 & 6 & 50 & 7.4 \% & 1.95[0.84,4.56] \\ \text { Subtotal (95\% Cl) } & & 1459 & & 2547 & \mathbf{8 3 . 2 \%} & \mathbf{0 . 8 5}[0.61,1.18]\end{array}$

Total events $185 \quad 429$

Heterogeneity: $\mathrm{Tau}^{2}=0.14 ; \mathrm{Chi}^{2}=22.18, \mathrm{df}=7(\mathrm{P}=0.002) ; \mathrm{I}^{2}=68 \%$

Test for overall effect: $Z=1.00(P=0.32)$

without indications for OAC

$\begin{array}{lrrrrrr}\text { Dangas, } 2020 & 56 & 711 & 35 & 702 & 12.4 \% & 1.58[1.05,2.38] \\ \text { De Backer O,2020 } & 8 & 115 & 3 & 116 & 4.3 \% & 2.69[0.73,9.89] \\ \text { Subtotal }(95 \% \mathrm{Cl}) & & 826 & & 818 & 16.8 \% & 1.66[1.12,2.45]\end{array}$

Total events $\quad 64 \quad 38$

Heterogeneity: $\mathrm{Tau}^{2}=0.00 ; \mathrm{Chi}^{2}=0.59, \mathrm{df}=1(\mathrm{P}=0.44) ; \mathrm{I}^{2}=0 \%$

Test for overall effect: $Z=2.54(P=0.01)$

Total $(95 \% \mathrm{Cl})$

2285

Total events 249

$3365100.0 \%$

Heterogeneity: $\mathrm{Tau}^{2}=0.17 ; \mathrm{Chi}^{2}=31.57, \mathrm{df}=9(\mathrm{P}=0.0002) ; \mathrm{I}^{2}=71 \%$

Test for overall effect: $Z=0.23(P=0.82)$

Test for subaroun differences: $\mathrm{Chi}^{2}=6.66 . \mathrm{df}=1(\mathrm{P}=0.010) . \mathrm{I}^{2}=85.0 \%$
M-H. Random. $95 \% \mathrm{Cl}$

$0.96[0.70,1.32]$

\section{Figure 2}

\section{Results of all-cause mortality}

NOACs standard care

Study or Subgroup Events Total Events with indications for $\mathrm{OAC}$ (no more than 12m)

$\begin{array}{lrrrrr}\text { Butt,2019 } & 15 & 219 & 54 & 516 & 12.8 \% \\ \text { Geis,2018 } & 12 & 154 & 11 & 172 & 9.3 \% \\ \text { Jochheim,2019 } & 54 & 326 & 78 & 636 & 16.7 \% \\ \text { Mangner,2019 } & 16 & 182 & 16 & 117 & 11.1 \% \\ \text { Seeger,2017 } & 19 & 81 & 6 & 50 & 8.6 \% \\ \text { Subtotal (95\% Cl) } & & 962 & & 1491 & \mathbf{5 8 . 5 \%} \\ \text { Total events } & 116 & & 165 & & \end{array}$

Heterogeneity: $\mathrm{Tau}^{2}=0.12 ; \mathrm{Chi}^{2}=9.46, \mathrm{df}=4(\mathrm{P}=0.05) ; \mathrm{I}^{2}=58 \%$

Test for overall effect: $Z=0.19(P=0.85)$

with indications for $\mathrm{OAC}$ (more than $12 \mathrm{~m}$ )

$\begin{array}{lllrrr}\text { Kalogeras,2020 } & 13 & 115 & 16 & 102 & 10.7 \% \\ \text { Kawashima,2020 } & 23 & 227 & 41 & 176 & 14.1 \% \\ \text { Kosmidou,2019 } & 33 & 155 & 207 & 778 & 16.7 \% \\ \text { Subtotal (95\% CI) } & & 497 & & \mathbf{1 0 5 6} & \mathbf{4 1 . 5 \%} \\ \text { Total events } & 69 & & 264 & & \end{array}$

Heterogeneity: $\mathrm{Tau}^{2}=0.07 ; \mathrm{Chi}^{2}=4.43, \mathrm{df}=2(\mathrm{P}=0.11) ; \mathrm{I}^{2}=55 \%$

Test for overall effect: $Z=2.18(P=0.03)$

Total $(95 \% \mathrm{Cl})$

1459

$185 \quad 429$

Total events 185

$2547 \quad 100.0 \%$

Heterogeneity: $\mathrm{Tau}^{2}=0.14 ; \mathrm{Chi}^{2}=22.18, \mathrm{df}=7(\mathrm{P}=0.002) ; \mathrm{I}^{2}=68 \%$

Test for overall effect: $Z=1.00(P=0.32)$

Test for subaroun differences: $\mathrm{Chi}^{2}=2.79 . \mathrm{df}=1(\mathrm{P}=0.09) . \mathrm{I}^{2}=64.2 \%$
Risk Ratio

$0.65[0.38,1.13]$

$1.22[0.55,2.68]$

$1.35[0.98,1.86]$

$0.64[0.33,1.23]$

$1.95[0.84,4.56]$

$1.04[0.69,1.56]$

$0.72[0.36,1.42]$

$0.43[0.27,0.70]$

$0.80[0.58,1.11]$

$0.64[0.42,0.96]$

$0.85[0.61,1.18]$

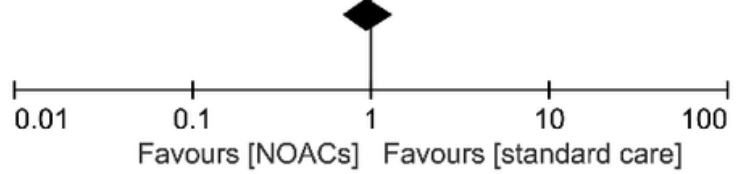

\section{Figure 3}


Subgroup analysis of all-cause mortality according to follow-up time

TSA is a Two-sided graph

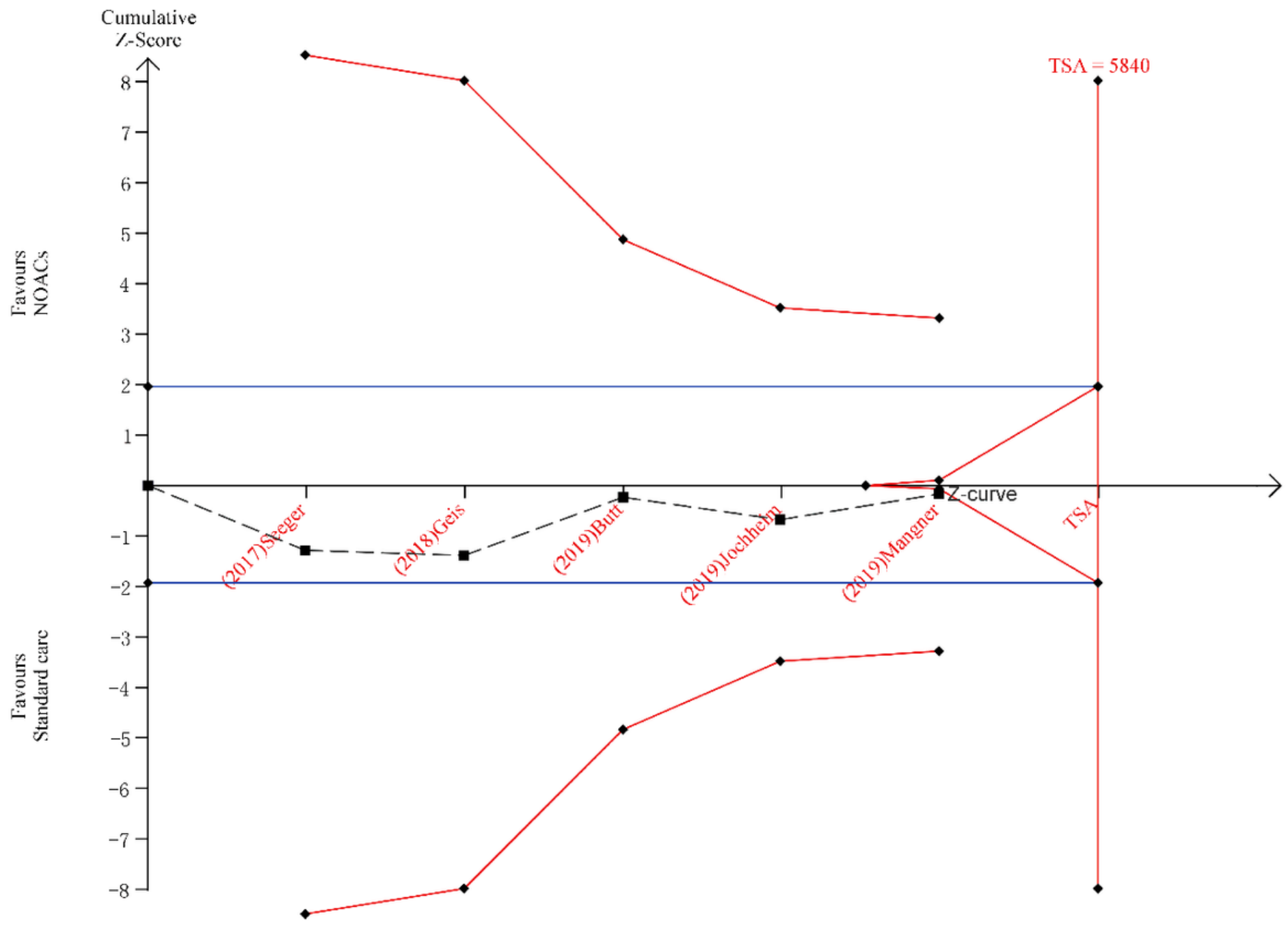

Figure 4

Cumulative analyses with O'Brien-Fleming sequential monitoring boundaries in all-cause mortality (follow-up time no more than $12 \mathrm{~m}$ ) 


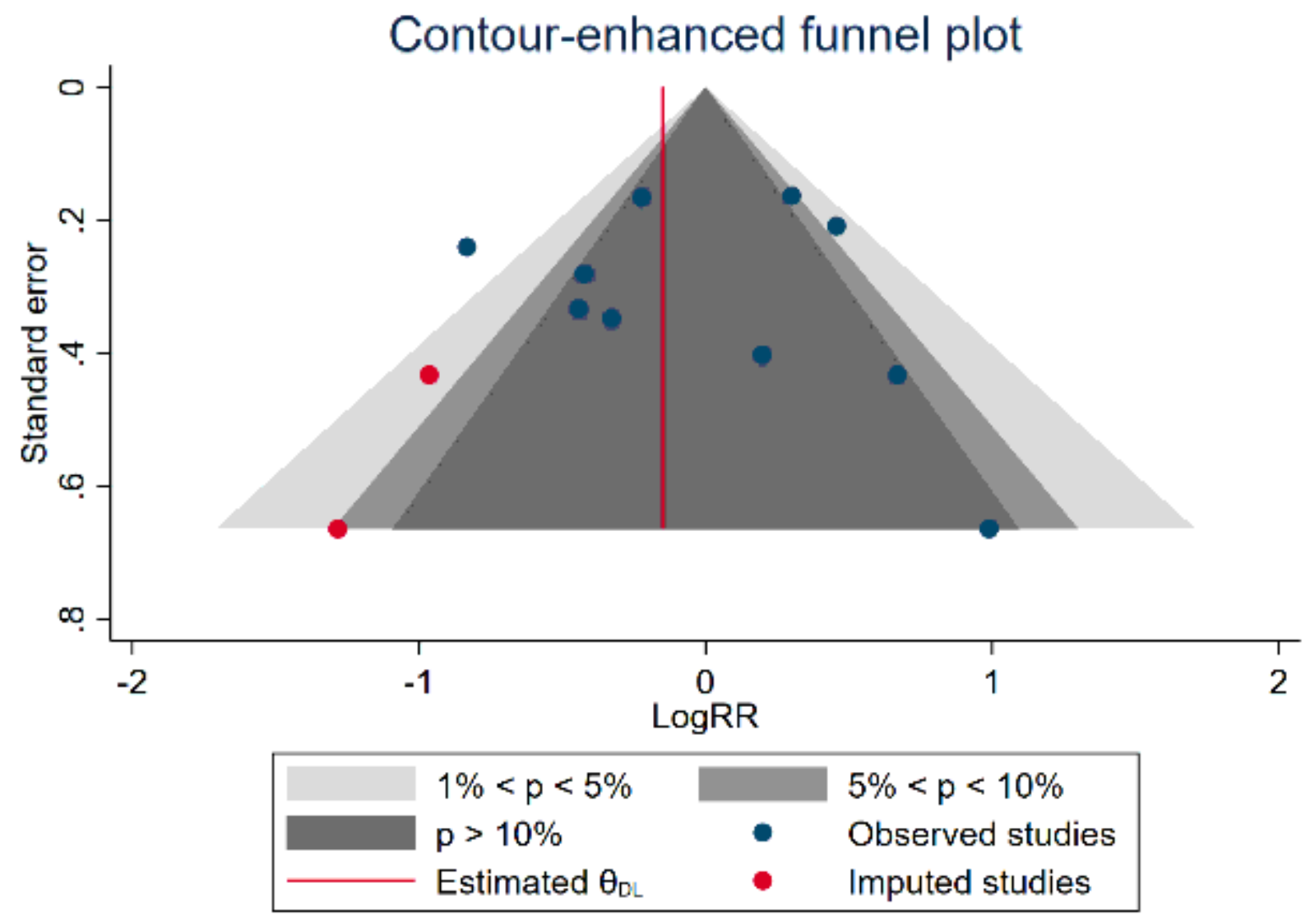

Figure 5

Contour enhanced funnel plot that showed imputed studies 
$\begin{array}{llll}\text { NOACs } & \text { standard care } & \text { Risk Ratio } & \text { Risk Ratio }\end{array}$

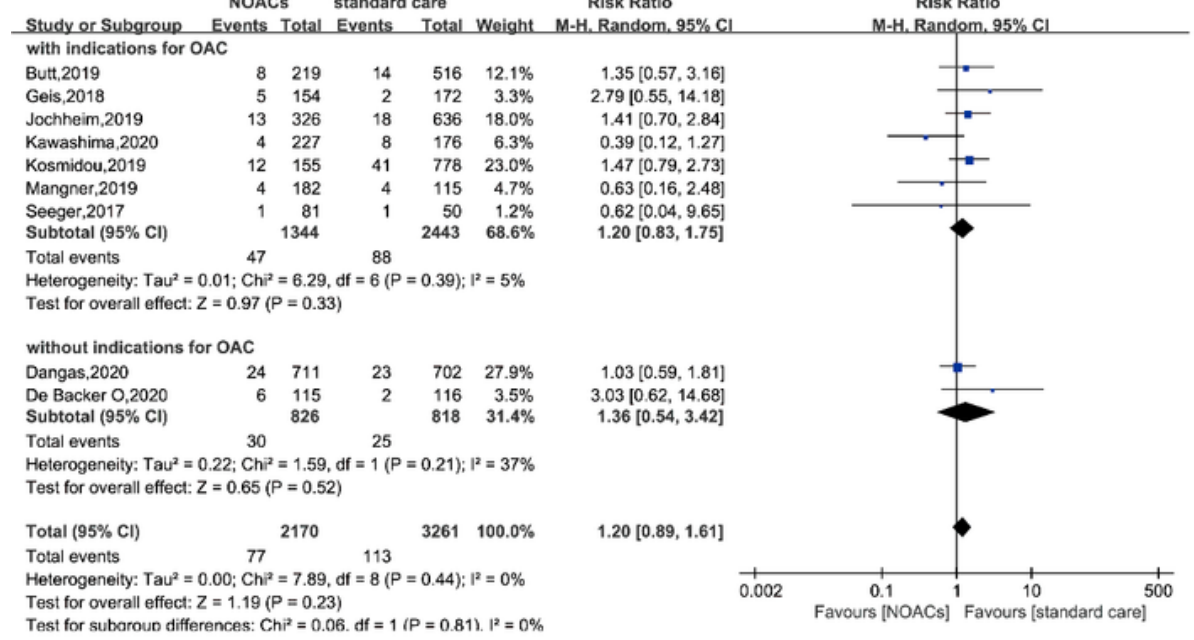

a

\begin{tabular}{|c|c|c|c|c|}
\hline \multirow{3}{*}{$\begin{array}{l}\text { Study or Subgroup } \\
\text { with indications for OAC }\end{array}$} & NOACs & \multicolumn{2}{|c|}{ standard care } & \\
\hline & Events Total & Events & Total & \\
\hline & & & & \\
\hline Jochheim,2019 & 326 & 4 & 636 & \\
\hline Tang, 2 & 21 & 9 & 83 & \\
\hline Yanag & 53 & 5 & 62 & \\
\hline Subtota & 400 & & 781 & \\
\hline
\end{tabular}

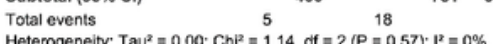

Heterogeneity: $\mathrm{Tau}^{2}=0.00 ; \mathrm{Ch}^{2}=1.14$, df $=2(P=0.57) ; \mathbf{l}^{2}=0 \%$
Test for overall effect: $Z=0.79(P=0.43)$

without indications for OAC

De Becker 022020 lor 0 AC

De Backer 0,2020

$\begin{array}{lllll}2 & 97 & 11 & 101 & 32.1 \%\end{array}$

Risk Ratio

Risk Ratio

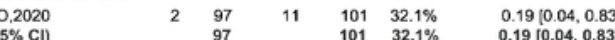

Total events

Heterogeneity: Not applicable
Test for overall effect: $Z=2.20(P=0.03)$

Total $(95 \% \mathrm{Cl})$

Total $(95 \% \mathrm{Cl})$

$\begin{array}{lll}497 \quad 882 & 100.0 \%\end{array}$

Heterogeneity: $\mathrm{Tau}^{2}=0.01 ; \mathrm{Chi}^{2}=3.04, \mathrm{df}=3(\mathrm{P}=0.39) ; \mathrm{l}^{2}=1 \%$

Test for overall effect: $Z=1.89(P=0.06)$

Test for subarous differences: $\mathrm{Chi}^{2}=1.87 . \mathrm{df}=1 / \mathrm{P}=0.17 \mathrm{l}, \mathrm{p}^{2}=46.5 \%$

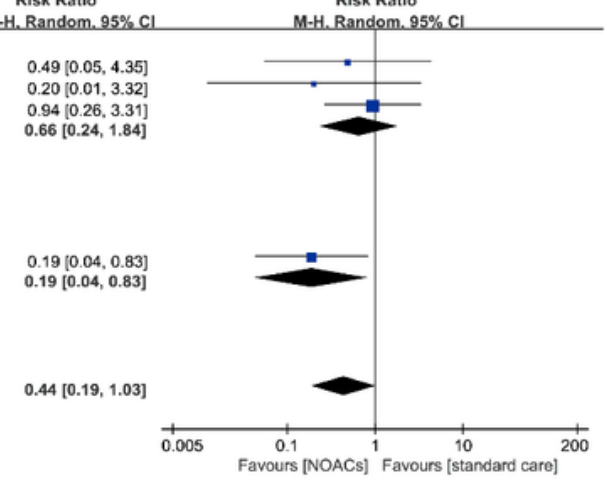

b

\begin{tabular}{lrrrrrr} 
& \multicolumn{1}{c}{ NOACs } & \multicolumn{3}{c}{ standard care } \\
Study or Subgroup & $\begin{array}{c}\text { Events } \\
\text { Total }\end{array}$ & Events & Total Weigh \\
\hline with indications for OAC & & & & & \\
Geis,2018 & 17 & 154 & 14 & 172 & $10.2 \%$ \\
Jochneim,2019 & 69 & 326 & 95 & 636 & $20.9 \%$ \\
Kosmidou,2019 & 39 & 155 & 234 & 778 & $20.5 \%$ \\
Mangner,2019 & 24 & 182 & 23 & 117 & $13.5 \%$ \\
Seeger,2017 & 20 & 81 & 7 & 50 & $8.3 \%$ \\
Subtotal (95\% Cl) & & 898 & & 1753 & 73.5 \\
Total events & 169 & & 373 & &
\end{tabular}

$\begin{array}{lcc}\text { Total events } & 169 & 373 \\ \text { Heterogeneity: } \text { Tau }^{2}=0.09 ; \mathrm{Ch}^{2}=11.69, \text { df }=4(P=0.02) ; \mathrm{I}^{2}=66 \%\end{array}$

Heterogeneity: Tau $^{2}=0.09 ; \mathrm{Ch}^{2}=11.69$,
Test for overall effect: $Z=0.49(P=0.62)$

without indications for $\mathrm{OAC}$

$\begin{array}{lllrrrr}\text { Dangas, } 2020 & 91 & 711 & 73 & 702 & 20.6 \% & 1.23[0.92,1.64] \\ \text { De Backer } 0,2020 & 14 & 115 & 5 & 116 & 5.9 \% & 2.82[1.05,7.59]\end{array}$

$\begin{array}{lllllll}\text { De Backer } 0,2020 & 14 & 115 & 5 & 116 & 5.9 \% & 2.82[1.05,7.59]\end{array}$

Subtotal $(95 \% \mathrm{Cl})$

105

$818 \quad 26.5 \%$

$1.62[0.75,3.50]$

Heterogeneity: $\mathrm{Tau}^{2}=0.21 ; \mathrm{Chi}^{2}=2.51, \mathrm{df}=1(\mathrm{P}=0.11) ; \mathrm{l}^{2}=60 \%$ Test for overall effect: $Z=1.23(P=0.22)$ $\begin{array}{llllll}\text { Total }(95 \% \mathrm{Cl}) & & 1724 & & 2571 & 100.0 \% \\ \text { Total events } & 274 & 451 & & \end{array}$ Total events

Risk Ratio H. Random. $95 \%$ Cl

Heterogeneity: $\mathrm{Tau}^{2}=0.07 ; \mathrm{Ch}^{2}=15.57, \mathrm{df}=6(\mathrm{P}=0.02) ; \mathrm{l}^{2}=61 \%$

Test for overall effect: $Z=1.19(P=0.24)$

Test for subaroun differences: $\mathrm{Ch}^{2}=0.86 . \mathrm{df}=1(\mathrm{P}=0.35) . \mathrm{I}^{2}=0 \%$

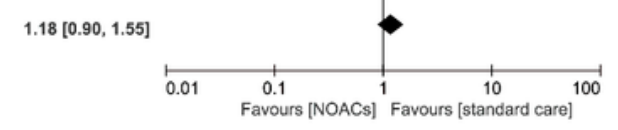

$\mathrm{c}$

\section{Figure 6}

Results of the efficacy outcomes: all stroke (a), valve thrombosis (b) and a composite endpoint(c) 
TSA is a Two-sided graph

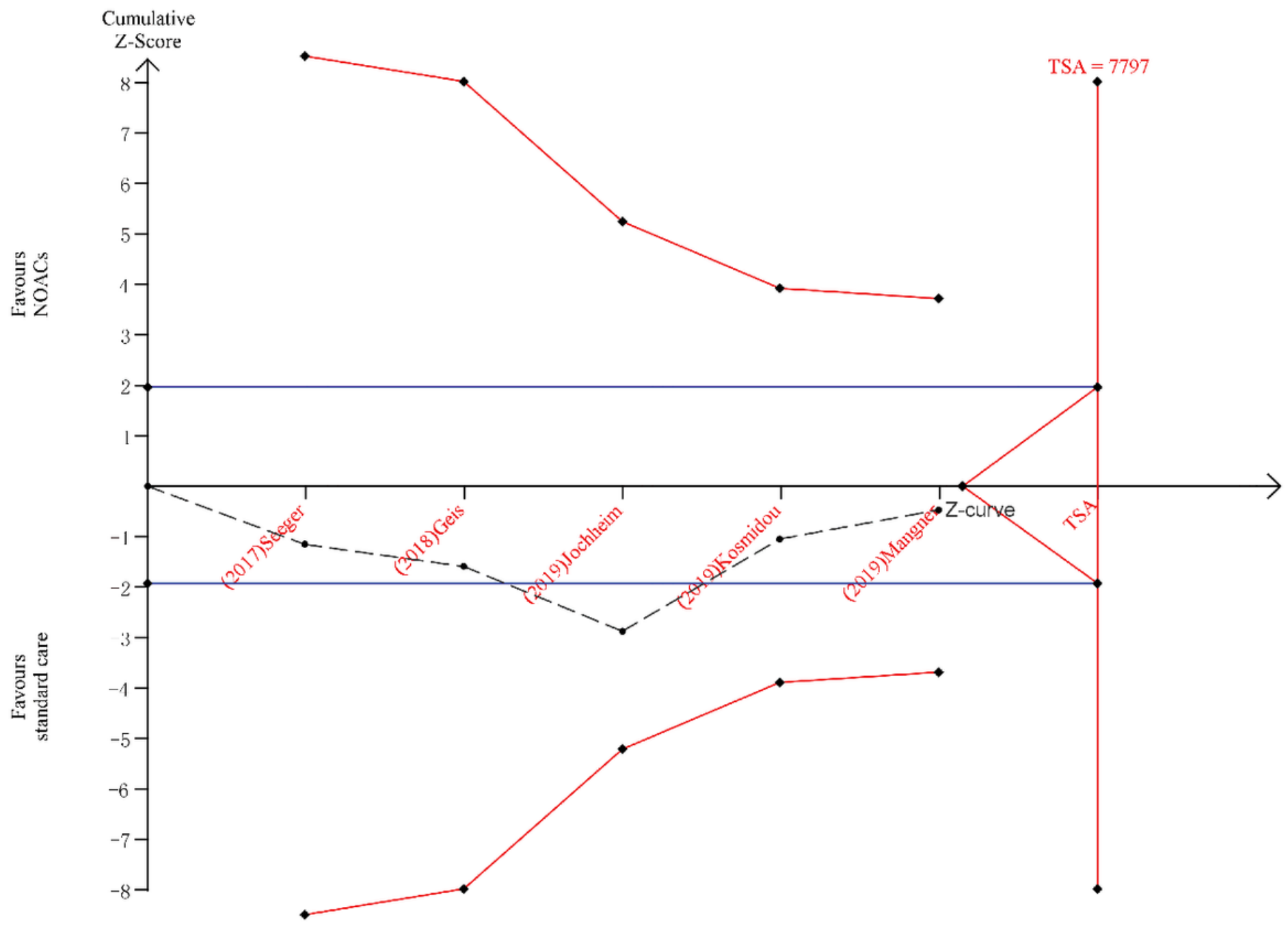

\section{Figure 7}

7 Cumulative analyses with O'Brien-Fleming sequential monitoring boundaries in a composite endpoint (with indications for OAC) 
NOACs standard care Risk Ratio

Study or Subgroup Events Total Events Total Weight M-H, Random, $95 \% \mathrm{Cl}$ with indications for OAC

$\begin{array}{lrrrrrr}\text { Butt,2019 } & 11 & 219 & 28 & 516 & 7.1 \% & 0.93[0.47,1.83] \\ \text { Geis,2018 } & 3 & 154 & 3 & 172 & 1.3 \% & 1.12[0.23,5.45] \\ \text { Jochheim,2019 } & 67 & 326 & 143 & 636 & 49.3 \% & 0.91[0.71,1.18] \\ \text { Kalogeras,2020 } & 9 & 115 & 6 & 102 & 3.3 \% & 1.33[0.49,3.61] \\ \text { Kawashima,2020 } & 8 & 227 & 11 & 176 & 4.1 \% & 0.56[0.23,1.37] \\ \text { Kosmidou,2019 } & 8 & 155 & 43 & 778 & 6.1 \% & 0.93[0.45,1.95] \\ \text { Mangner,2019 } & 25 & 182 & 19 & 116 & 10.9 \% & 0.84[0.48,1.45] \\ \text { Seeger,2017 } & 4 & 81 & 3 & 50 & 1.5 \% & 0.82[0.19,3.53] \\ \text { Subtotal (95\% Cl) } & & 1459 & & 2546 & 83.6 \% & 0.90[0.74,1.10]\end{array}$

Total events $\quad 135 \quad 256$

Heterogeneity: $\mathrm{Tau}^{2}=0.00 ; \mathrm{Chi}^{2}=1.83, \mathrm{df}=7(\mathrm{P}=0.97) ; \mathrm{I}^{2}=0 \%$

Test for overall effect: $Z=1.05(P=0.29)$

without indications for OAC

$\begin{array}{lrrrrrr}\text { Dangas,2020 } & 42 & 711 & 30 & 702 & 15.7 \% & 1.38[0.88,2.18] \\ \text { De Backer O,2020 } & 4 & 115 & 1 & 116 & 0.7 \% & 4.03[0.46,35.55] \\ \text { Subtotal }(95 \% \mathrm{Cl}) & & 826 & & 818 & 16.4 \% & 1.45[0.92,2.26] \\ \text { Total events } & 46 & & 31 & & & \end{array}$

Heterogeneity: $\mathrm{Tau}^{2}=0.00 ; \mathrm{Chi}^{2}=0.90, \mathrm{df}=1(\mathrm{P}=0.34) ; \mathrm{I}^{2}=0 \%$

Test for overall effect: $Z=1.62(P=0.11)$

Total $(95 \% \mathrm{Cl})$

Total events 2285 181

$3364100.0 \%$

Heterogeneity: $\mathrm{Tau}^{2}=0.00 ; \mathrm{Chi}^{2}=6.37, \mathrm{df}=9(\mathrm{P}=0.70) ; \mathrm{I}^{2}=0 \%$

Test for overall effect: $Z=0.31(P=0.76)$

Test for subaroun differences: $\mathrm{Chi}^{2}=3.63 . \mathrm{df}=1(\mathrm{P}=0.06) . \mathrm{I}^{2}=72.5 \%$
Risk Ratio

M-H. Random. $95 \% \mathrm{Cl}$

$0.97[0.81,1.16]$

Figure 8

Results of the safety outcome

\section{Supplementary Files}

This is a list of supplementary files associated with this preprint. Click to download.

- SupplementaryMaterial.docx 